\title{
SEGURANÇA DO TRABALHO E MEDIDAS DE PROTEÇÃO NA CONSTRUÇÃO CIVIL
}

\section{Allefy Teles Sampaio', Ana Elisa Lavezo², Graziella Deldoto Coutinho ${ }^{3}$}

\footnotetext{
${ }^{1}$ Acadêmico do curso de Segurança do Trabalho, Centro Universitário de Maringá - UNICESUMAR. Bolsista PIC/ICETI telesallefy@gmail.com

${ }^{2}$ Orientadora, Doutora, Departamento de Pesquisa, UNICESUMAR. Pesquisadora do Instituto Cesumar de Ciência, Tecnologia e Inovação - ICETI, ana.lavezo@unicesumar.edu.br.

${ }^{3}$ Coorientadora, Especialista, Departamento de Pesquisa, UNICESUMAR. Pesquisadora do Instituto Cesumar de Ciência, Tecnologia e Inovação - ICETI, graziella.deldoto@unicesumar.edu.br
}

\section{RESUMO}

As atividades relacionadas à Construção Civil apresentam inúmeros fatores que podem comprometer a saúde dos trabalhadores. Falta de mão-de-obra qualificada e fiscalização escassa aumentam o índice de acidentes na Construção Civil. $\mathrm{Na}$ maioria das vezes, a segurança fornecida aos trabalhadores não está conforme as Normas Regulamentadoras. Deste modo, este trabalho será desenvolvido a fim de buscar as melhorias que as empresas do ramo da construção civil devem adotar para garantir a integridade física e mental dos trabalhadores, tendo como consequência, um trabalho mais eficiente.

PALAVRAS-CHAVE: Construção Civil; Integridade do Trabalhador; Saúde dos Trabalhadores.

A Construção Civil é uma das mais importantes atividades para o desenvolvimento econômico, social e ambiental do nosso País, mas é, também, geradora de impactos ambientais e sociais, quer seja pelo consumo de recursos naturais, pela modificação da paisagem, pela geração de resíduos ou pelos numerosos registros de acidentes do trabalho (SINDUSCON, 2005).

A engenharia civil é uma área, que devido as suas características, são indústrias que se difere em muitas situações das demais indústrias. Isto acontece porque cada projeto que se inicia é tratado como um projeto praticamente novo, não havendo, muitas vezes, repetição das características dos empreendimentos. Além disso, na engenharia civil, quase sempre, o local onde se desenvolve o projeto é diferente do local onde se desenrola a obra, o que por si só cria incertezas que podem condicionar a qualidade final do projeto (SILVA, 2012).

Silva (2012) comenta que o trabalho nesta área pode ser realizado em condições precárias, uma vez que, a fase de construção se processa em contato com o meio externo, estando, muitas vezes, as pessoas, os materiais, os equipamentos e a própria obra expostos a intempéries que podem causar danos e, consequentemente, atrasos na obra e desvios de custos. Outra característica importante é o fato de exigir a intervenção de várias pessoas de áreas distintas, na maior parte das vezes, o que origina conflitos, quebras de informação e dificuldades de comunicação. Estas características, como muitas outras, tornam a engenharia civil, sujeita ao risco. Assim, sendo este é um ramo bastante complexo, torna-se essencial o conhecimento de técnicas capazes de identificar e tratar os riscos de forma que estes não prejudiquem a qualidade e o preço final do projeto (SILVA, 2012). 
O planejamento de um canteiro de obras tem por objetivo a melhor utilização do espaço físico disponível, de forma a possibilitar que homens e máquinas trabalhem com segurança e eficiência, principalmente através da minimização das movimentações de materiais, produtos e mãos de obra. O canteiro de obras deverá ser projetado e dimensionado antes do início da obra, de forma a viabilizar um ambiente de trabalho sadio e confortável para os trabalhadores. Para implantar uma cultura prevencionista e evitar acidentes de trabalho, faz-se necessário a conscientização do trabalhador, seja através de treinamentos, palestras, cursos de segurança, cartazes e afins, fatores estes, determinantes para um decorrer dos serviços de obra sem ocorrência de prejuízos físicos ao mesmo.

\section{MATERIAIS E MÉTODOS}

A construção civil é considerada um ramo que emprega muitos trabalhadores e o índice de acidentes de trabalho é considerado um dos mais altos comparando-se com as demais indústrias. Entende-se que analisando os riscos, os métodos de prevenção de acidentes e as medidas de proteção adotadas nos canteiro de obras são possíveis ações de correções para iniciarem uma conscientização com o intuito de reduzir os índices de acidentes de trabalho, tornando-se desta forma um ambiente de trabalho mais seguro.

Neste trabalho serão identificados os dados sobre acidente de trabalho em nível nacional e posteriormente seccionar por regiões brasileiras. Os riscos ocupacionais, a serem investigados são: riscos físicos, químicos, biológicos, ergonômicos e de acidentes. Serão identificados os métodos de prevenção de acidentes e as medidas de proteção adotadas nos canteiros de obras, a fim de que de posse desses dados de antecipação, reconhecimento, avaliação e controle, sejam reconhecidas alternativas para adoção de métodos, insumos e treinamentos, a fim de neutralizar e/ou minimizar os danos causados aos trabalhadores da construção civil.

\section{$3 \quad$ RESULTADOS E DISCUSSÕES}

Espera-se com esse trabalho mapear o número de acidentes de trabalho, suas causas, os riscos inerentes a profissão do trabalhador da construção civil, com esses dados verificar se as medidas de proteção coletivas, administrativas se são suficientes e se é necessário adoção de medidas proteção individuais.

\section{CONSIDERAÇÕES FINAIS}

Conclui-se que a mais eficiente maneira de evitar acidentes do trabalho é o cumprimento das Normas Regulamentadoras, mas para que isso seja seguido é necessário um trabalho educativo intenso. A falta de informação dos funcionários aumenta a probabilidade de acidentes.

Esse trabalho tem o intuito de divulgar informações sobre a segurança do trabalho e as medidas de proteção, eficazes na minimização de acidentes de trabalho e suprir algo que é negligenciado pelas construtoras. É necessário conscientizar os empresários sobre a necessidade em investimento em prevenção de acidentes voltadas para o trabalho. 


\section{REFERÊNCIAS}

CÔRTES, A.S.; SILVA, L.S., A importância da conscientização dos

trabalhadores da construção civil. 2011. Monografia (Curso de Engenharia Civil), Universidade Vale do Rio Doce, Governador Valadares.

LEGIS WEB, Informação rápida e confiável. Portaria SST no 25 de 29 dez. de 1994. Aprova a Norma Regulamentadora no 9 - Riscos Ambientais, e dá outras providências. 30 de dez. de 1994. Disponível em:

https://www.legisweb.com.br/legislacao/?id=181316. Acesso em: 29 Mar 2019.

MARTINS, M.S., Diretrizes para elaboração de medidas de Prevenção contra Quedas de Altura em edificações. 2004. Dissertação (Mestrado em Construção Civil), Universidade Federal de São Carlos, São Carlos.

NORMAS REGULAMENTADORAS. NR-9. Programa de prevenção de riscos ambientais. 8 jun. de 1978. Disponível em:

https://enit.trabalho.gov.br/portal/images/Arquivos_SST/SST_NR/NR-09.pdf. Acesso em: 28 Mar 2019.

PACHECO, A.C., O uso de Equipamentos de Proteção Individual e Coletivo conforme Programa de Condições e Meio Ambiente de Trabalho -

PCMAT. 2010. Trabalho (Curso de Engenharia Civil), Universidade Estadual de Feira de Santana, Feira de Santana.

SILVA, Vanessa Fernandes. Análise De Risco Na Construção - Guia De

Procedimentos Para Gestão. Mestrado Integrado Em Engenharia Civil 2009/2010. Faculdade De Engenharia Da Universidade Do Porto. 2012. Disponível em: https://repositorio-aberto.up.pt/bitstream/10216/72676/1/000154217.pdf. Acesso em: 28 Mar 2019. 